\title{
Death receptor-independent FADD signalling triggers hepatitis and hepatocellular carcinoma in mice with liver parenchymal cell-specific NEMO knockout
}

\author{
H Ehlken ${ }^{1,2,7}$, S Krishna-Subramanian ${ }^{1,7}$, L Ochoa-Callejero ${ }^{1,3}$, V Kondylis ${ }^{1}$, NE Nadii ${ }^{1}$, BK Straub ${ }^{4}$, P Schirmacher ${ }^{4}$, H Walczak ${ }^{5}$, \\ G Kollias ${ }^{6}$ and M Pasparakis ${ }^{\star 1}$
}

Hepatocellular carcinoma (HCC) usually develops in the context of chronic hepatitis triggered by viruses or toxic substances causing hepatocyte death, inflammation and compensatory proliferation of liver cells. Death receptors of the TNFR superfamily regulate cell death and inflammation and are implicated in liver disease and cancer. Liver parenchymal cell-specific ablation of $\mathrm{NEMO} / \mathrm{KK} \gamma$, a subunit of the $\boldsymbol{I}_{\boldsymbol{1}} \mathrm{B}$ kinase (IKK) complex that is essential for the activation of canonical NF- $\kappa \mathrm{B}$ signalling, sensitized hepatocytes to apoptosis and caused the spontaneous development of chronic hepatitis and HCC in mice. Here we show that hepatitis and HCC development in NEMO ${ }^{\mathrm{LPC}-\mathrm{KO}}$ mice is triggered by death receptor-independent FADD-mediated hepatocyte apoptosis. TNF deficiency in all cells or conditional LPC-specific ablation of TNFR1, Fas or TRAIL-R did not prevent hepatocyte apoptosis, hepatitis and HCC development in NEMO ${ }^{\mathrm{LPC}-\mathrm{KO}}$ mice. To address potential functional redundancies between death receptors we generated and analysed NEMO ${ }^{\text {LPC-KO }}$ mice with combined LPC-specific deficiency of TNFR1, Fas and TRAIL-R and found that also simultaneous lack of all three death receptors did not prevent hepatocyte apoptosis, chronic hepatitis and HCC development. However, LPC-specific combined deficiency in TNFR1, Fas and TRAIL-R protected the NEMOdeficient liver from LPS-induced liver failure, showing that different mechanisms trigger spontaneous and LPS-induced hepatocyte apoptosis in NEMO ${ }^{\mathrm{LPC}-\mathrm{KO}}$ mice. In addition, NK cell depletion did not prevent liver damage and hepatitis. Moreover, NEMO ${ }^{\mathrm{LC}-K O}$ mice crossed into a RAG-1-deficient genetic background-developed hepatitis and HCC. Collectively, these results show that the spontaneous development of hepatocyte apoptosis, chronic hepatitis and HCC in NEMO ${ }^{\text {LPC-KO }}$ mice occurs independently of death receptor signalling, NK cells and B and T lymphocytes, arguing against an immunological trigger as the critical stimulus driving hepatocarcinogenesis in this model.

Cell Death and Differentiation (2014) 21, 1721-1732; doi:10.1038/cdd.2014.83; published online 27 June 2014

Liver cancer is one of the most common malignancies and the third leading cause of cancer-related deaths worldwide. $^{1,2}$ Liver cancer predominantly arises in the context of chronic inflammatory conditions, most notably in virus hepatitis (HBV and $\mathrm{HCV}$ ). ${ }^{1,2}$ Although infectious agents are the primary cause of liver cancer worldwide, the incidence in western countries is rising due to the increase in obesity and non-alcoholic steatohepatitis. ${ }^{3}$ The pathogenesis of hepatocellular carcinoma (HCC) is incompletely understood and it is plausible that the different underlying aetiologies determine a distinct context for liver carcinogenesis. However, the prevailing universal concept is that continuous liver parenchymal damage and hepatocyte cell death drive compensatory proliferation and within the context of a chronically inflamed liver tissue mutations and epigenetic changes accumulate eventually transforming hepatocytes into malignant cells. Therefore, understanding the tissue-intrinsic processes that determine cell death and chronic inflammation resulting in hepatocarcinogenesis is a critical need in order to design more effective therapeutic strategies.

The nuclear factor $\kappa \mathrm{B}(\mathrm{NF}-\kappa \mathrm{B})$ pathway is implicated in cancer development in particular in the context of chronic inflammation. ${ }^{4,5}$ In relation to liver cancer, NF- $\kappa$ B signalling has been implicated in the pathogenesis of hepatitis, liver fibrosis, cirrhosis and HCC. ${ }^{6,7}$ The IKK complex, composed of

\footnotetext{
${ }^{1}$ Institute for Genetics, Center for Molecular Medicine (CMMC), Cologne Excellence Cluster on Cellular Stress Responses in Aging-Associated Diseases (CECAD), University of Cologne, Joseph-Stelzmann-Strasse 26, Cologne D-50931, Germany; ${ }^{2}$ University Medical Center Hamburg-Eppendorf, Hamburg D-20246, Germany; ${ }^{3}$ Oncology Area, Center for Biomedical Research of La Rioja (CIBIR), 26006 Logroño, Spain; ${ }^{4}$ Institute of Pathology, University Hospital Heidelberg, INF 224, 69120 Heidelberg, Germany; ${ }^{5}$ Centre for Cell Death, Cancer and Inflammation (CCCI), UCL Cancer Institute, University College London, 72 Huntley Street, WC1E 6BT London, UK and ${ }^{6}$ B.S.R.C. Alexander Fleming, 34 Fleming Street, Vari 16672, Greece

${ }^{*}$ Corresponding author: M Pasparakis, Institute for Genetics, Center for Molecular Medicine (CMMC), Cologne Excellence Cluster on Cellular Stress Responses in Aging-Associated Diseases (CECAD), University of Cologne, Joseph-Stelzmann-Strasse 26, Cologne D-50931, Germany. Tel: +49 221 47884349 ; E-mail: pasparakis@uni-koeln.de

${ }^{7}$ These authors contributed equally to this work.

Abbreviations: NEMO, NF-kappa B essential modulator; TNF, tumour necrosis factor; FADD, Fas-associated with death domain; Trail, TNF-related apoptosis-inducing ligand; LPS, Lipopolysaccharide; LPC, liver parenchymal cells; DR5, death receptor 5; ALT, alanine aminotransferase; RIP, receptor interacting protein; Ifng, interferon gamma; Ccnd1, cyclin D1; CK-19, cytokeratin 19; TBP, TATA-binding protein; EBSS, Eagle's balanced salt solution

Received 27.3.14; revised 02.5.14; accepted 06.5.14; Edited by V Dixit; published online 27.6.14
} 
two catalytic subunits, IKK1/IKK $\alpha$ and IKK2/IKK $\beta$, and a regulatory subunit termed $\mathrm{NEMO} / \mathrm{IKK} \gamma$, activates $\mathrm{NF}-\kappa \mathrm{B}$ by phosphorylating inhibitor of $\mathrm{NF}-\kappa \mathrm{B}(\mathrm{I} \kappa \mathrm{B})$ proteins targeting them for degradation by the proteasome and thus allowing the nuclear accumulation of $\mathrm{NF}-\kappa \mathrm{B}$ dimers. ${ }^{5} \mathrm{IKK} 2$ is primarily responsible for targeting and degrading $\mathrm{I}_{\kappa} \mathrm{B} \alpha$ thus inducing canonical NF- $\kappa \mathrm{B}$ activation, although the two kinases show some degree of functional redundancy in controlling canonical $\mathrm{NF}-\kappa \mathrm{B}$ signalling. ${ }^{5,8} \mathrm{NEMO} / \mathrm{IKK} \gamma$ is indispensable for activation of canonical NF- $\kappa$ B signalling. ${ }^{9-11}$

$\mathrm{NF}-\kappa \mathrm{B}$ signalling was proposed to exhibit tumour promoter or tumour suppressor properties in different models of liver cancer. In the $\mathrm{Mdr}^{-1}$ mouse model of inflammation-driven liver carcinogenesis, NF- $\kappa$ B inhibition caused by transgenic $\mathrm{I} \kappa \mathrm{B} \alpha$ super-repressor expression in hepatocytes inhibited HCC progression. ${ }^{12}$ Moreover, hepatocyte-restricted ablation of IKK2 prevented hepatitis and liver tumorigenesis induced by overexpression of lymphotoxins $\alpha$ and $\beta$ in hepatocytes. ${ }^{13}$ However, mice with hepatocyte-specific IKK2 ablation developed more tumours induced by a single injection of the chemical carcinogen diethylnitrosamine, ${ }^{14}$ revealing a tumour suppressor role of $\mathrm{NF}-\kappa \mathrm{B}$ in this context.

Studies in mice lacking NEMO specifically in liver parenchymal cells (LPCs) further supported a tumour suppressor function of IKK/NF- $\kappa$ B signalling in liver cancer. NEMO ${ }^{\mathrm{LCC}-\mathrm{KO}}$ mice showed spontaneous hepatocyte apoptosis resulting in chronic steatohepatitis and the development of HCC by the age of 1 year. ${ }^{15}$ LPC-specific ablation of Fas-Associated with Death Domain (FADD or MORT1), an adapter protein essential for the recruitment of caspase- 8 to the Death Inducing Signalling Complex and the induction of death receptor-mediated apoptosis, ${ }^{16}$ prevented both spontaneous and LPS-induced apoptosis of NEMO-deficient hepatocytes and the development of steatohepatitis. ${ }^{15}$ In addition, LPCspecific knockout of caspase-8 inhibited spontaneous hepatocyte apoptosis and HCC development in NEMO ${ }^{\mathrm{LPC}-\mathrm{KO}}$ mice, although it caused non-apoptotic hepatocyte death and cholestasis. ${ }^{17}$ Given the essential role of FADD and caspase- 8 in mediating apoptosis downstream of death receptors, ${ }^{16}$ we hypothesized that death receptor-mediated apoptosis of NEMO-deficient hepatocytes drives the development of hepatitis and HCC in NEMO ${ }^{\mathrm{LPC}-\mathrm{KO}}$ mice. The three main death receptors of the TNF receptor superfamily that are capable of inducing caspase-8-mediated apoptosis are TNFR1, Fas/CD95 and TRAIL-R/DR5. ${ }^{16}$ To address the role of death receptor-induced apoptosis in triggering the spontaneous death of NEMO-deficient hepatocytes and the development of steatohepatitis and HCC, we generated and analysed NEMO ${ }^{\mathrm{LPC}-\mathrm{KO}}$ mice lacking TNFR1, Fas or TRAIL-R specifically in LPCs. Surprisingly, we found that LPC-specific knockout of each of the death receptors alone but also combined deficiency of TNFR1, Fas and TRAIL-R in LPCs did not prevent spontaneous hepatocyte apoptosis, hepatitis and HCC development in NEMO ${ }^{\mathrm{LPC}-\mathrm{KO}}$ mice. In addition, knockout of TNF in all cells also did not protect NEMO ${ }^{\mathrm{LPC}-K O}$ mice from hepatocyte death, hepatitis and HCC. Collectively, these results demonstrate that TNFR1, Fas and TRAIL-R are not required for the development of chronic liver damage and $\mathrm{HCC}$ in NEMO ${ }^{\mathrm{LPC}-\mathrm{KO}}$ mice.

\section{Results}

\section{LPC-specific FADD ablation prevents liver carcinogenesis} in NEMO ${ }^{\text {LPC-KO }}$ mice. FADD is essential for the recruitment and activation of caspase- 8 and the induction of apoptosis downstream of death receptors including TNFR1, Fas and TRAIL-R. We showed previously that LPC-specific FADD deficiency strongly reduced early hepatitis in NEMO ${ }^{\mathrm{LPC}-K O}$ mice as indicated by significantly lower serum alanine aminotransferase (ALT) levels and reduced hepatocyte apoptosis and compensatory proliferation. ${ }^{15}$ To further characterize the role of FADD in the spontaneous development of hepatitis and HCC in NEMO ${ }^{\mathrm{LPC}-K O}$ mice, we analysed groups of NEMO ${ }^{\mathrm{LPC}-K O} / F A D D^{\mathrm{LPC}-K O}$ mice at the age of 8 weeks or 1 year. NEMO ${ }^{\mathrm{LPC}-K O} / \mathrm{FADD}^{\mathrm{LPC}-K O}$ mice had average serum ALT levels of about $200 \mathrm{U} / \mathrm{l}$, which were significantly reduced compared with NEMOLPC-KO mice but higher than the background levels of wild-type control mice, indicating that FADD deficiency did not fully prevent liver damage in NEMO ${ }^{\mathrm{LPC}-\mathrm{KO}}$ mice (Figure 1a). Histological analysis showed that FADD deficiency prevented hepatocyte apoptosis as indicated by the lack of active caspase-3positive cells in the liver of NEMO ${ }^{\mathrm{LPC}-\mathrm{KO}} / \mathrm{FADD} \mathrm{D}^{\mathrm{LPC}-\mathrm{KO}}$ mice (Figure $1 \mathrm{~b}$ and Supplementary Figure S2C). However, the liver of 8-week-old NEMO ${ }^{\mathrm{LPC}-K O} /$ FADD ${ }^{\mathrm{LPC}-K O}$ mice displayed some focal necrotic lesions that were surrounded by granulocytes (Figure 1b), indicating that FADD ablation protected NEMO-deficient hepatocytes from apoptosis but triggered focal necrotic hepatocyte death resulting in mildly elevated serum ALT levels. Given the important role of FADD in preventing RIPK3-mediated necroptosis, ${ }^{18-20}$ it is likely that the necrotic foci are caused by necroptotic hepatocyte death that occurs focally in the livers of NEMO ${ }^{\mathrm{LPC}-\mathrm{KO} /}$ FADD ${ }^{\mathrm{LPC}-\mathrm{KO}}$ mice. Hepatocyte proliferation was reduced in the livers of NEMO ${ }^{\mathrm{LPC}-\mathrm{KO}} / \mathrm{FADD}{ }^{\mathrm{LPC}-\mathrm{KO}}$ compared with NEMO ${ }^{\mathrm{LPC}-\mathrm{KO}}$ mice as indicated by less Ki67-positive hepatocytes and lower mRNA expression of CyclinD1 (Figures $1 b$ and $c$ and Supplementary Figure S2D). In addition, immunostaining for cytokeratin 19 (CK19) revealed that FADD deficiency prevented oval cell expansion in NEMOLPC-KO/ FADD $^{\mathrm{LPC}-\mathrm{KO}}$ mice (Supplementary Figure S2B). Moreover, although TNF expression was not altered the levels of IFN $\gamma$ mRNA were reduced in the liver of NEMO ${ }^{\mathrm{LPC}-K O} / F A D D^{\mathrm{LPC}-K O}$ mice indicating overall reduced inflammation, consistent with the histological analysis showing reduced numbers of F4/80-positive macrophages (Figures $1 \mathrm{~b}$ and c).

To address the role of FADD in HCC development in NEMO ${ }^{\mathrm{LCC}-\mathrm{KO}}$ mice, we examined the livers of NEMO ${ }^{\mathrm{LPC}-\mathrm{KO}}$ / FADD ${ }^{\text {LPC-KO }}$ mice at the age of 1 year or more for spontaneous tumour development. Although their serum ALT levels were similar to those of NEMO ${ }^{\mathrm{LPC}-\mathrm{KO}}$ mice, we found that none of the NEMO ${ }^{\mathrm{LPC}-K O} / F A D D^{\mathrm{LPC}-K O}$ mice examined at the age of 1-1.5 years $(n=18)$ showed macroscopically visible liver tumours (Figures $1 \mathrm{~d}$ and e and Supplementary Figure S1). Histological examination also confirmed the lack of tumours or dysplastic premalignant precursor lesions (Figure 1e). Therefore, FADD deficiency fully protected NEMO $\mathrm{LPC}-\mathrm{KO}$ mice from the development of HCC, demonstrating that FADD is essential for spontaneous hepatocarcinogenesis in this model. 

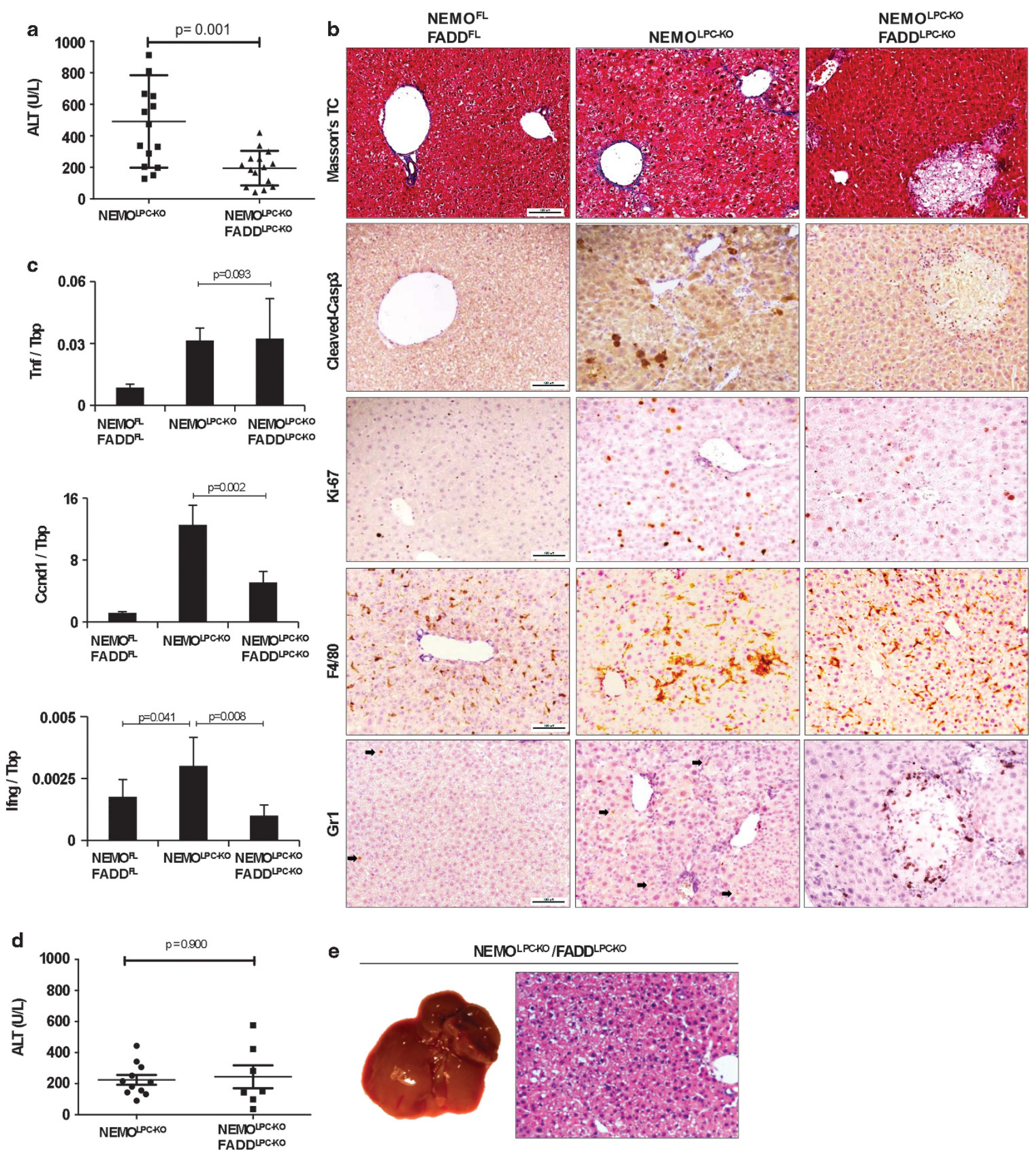

e NEMOLPCKO/FADD

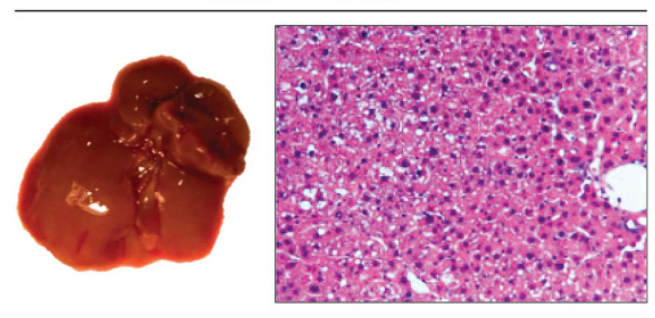

Figure 1 FADD deletion decreases liver damage and inflammation and prevents HCC in NEMO ${ }^{L P C-K O}$ mice. (a) Serum ALT levels in 8-week-old mice. (b) Liver sections of 8-week-old mice stained with Masson's Trichrome and for cleaved caspase-3, Ki-67, F4/80 and Lys6G/Gr1. Arrows indicate GR1-positive cells (granulocytes) (c) qRT-PCR analysis of mRNA isolated from total liver tissue of 8-week-old mice ( $n=5$ per genotype, expression normalized to Tbp). (d) Serum ALT levels from 1-year-old mice. (e) Representative macroscopic picture and H\&E-stained liver section of 1-year-old NEMO ${ }^{\text {LPC-KO} / F A D D ~}{ }^{\mathrm{LPC}-K O}$ mice

TNF is dispensable for spontaneous hepatocyte death, hepatitis and HCC development in NEMO ${ }^{\mathrm{LPC}-\mathrm{KO}}$ mice. The finding that FADD deficiency prevented spontaneous hepatocyte apoptosis and HCC development in NEMO ${ }^{\text {LPC-KO }}$ mice suggested that hepatitis and liver cancer in these mice are driven by death receptor-induced apoptosis. NF- $\kappa \mathrm{B}$ inhibition sensitizes cells to TNF-induced apoptosis and p65 or IKK2 knockout mice die during embryogenesis due to 
TNF-mediated liver degeneration. ${ }^{21,22}$ The expression of TNF is upregulated in the NEMO-deficient livers (Figure 2c); therefore, we hypothesized that TNF-mediated hepatocyte apoptosis drives hepatitis and HCC development in NEMO ${ }^{\mathrm{LPC}-\mathrm{KO}}$ mice. To address the role of TNF, we crossed NEMO ${ }^{\mathrm{LPC}-\mathrm{KO}}$ mice with mice lacking $\mathrm{TNF}^{23}$ to generate $\mathrm{NEMO}^{\mathrm{LPC}-\mathrm{KO}} / \mathrm{Tnf}^{-1-}$ mice. Surprisingly, 8-weekold $\mathrm{NEMO}^{\mathrm{LPC}-\mathrm{KO}} / \mathrm{Tnf}^{-1-}$ mice exhibited similarly increased serum ALT levels compared with NEMO ${ }^{\mathrm{LPC}-K O}$ mice, demonstrating that TNF deficiency did not prevent spontaneous liver damage in NEMO ${ }^{\mathrm{LPC}-\mathrm{KO}}$ mice (Figure 2a). Histological analysis revealed that the livers of $\mathrm{NEMO}^{\mathrm{LPC}-\mathrm{KO}} / \mathrm{Tnf}^{-{ }^{-}-}$mice had increased numbers of active caspase-3-positive apoptotic hepatocytes, increased hepatocyte proliferation, oval cell expansion, fibrosis and increased infiltration of macrophages and neutrophils
(Figure $2 \mathrm{~b}$ and Supplementary Figure S2). Consistent with the increased presence of proliferating hepatocytes, livers

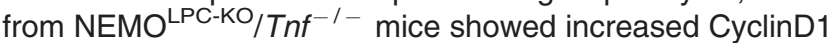
expression (Figure 2c). These results showed that TNF deficiency could not prevent hepatocyte apoptosis and the development of spontaneous hepatitis in young NEMO ${ }^{\mathrm{LPC}-\mathrm{KO}}$ mice. To assess whether the lack of TNF could prevent the spontaneous development of HCC, we analysed the livers of $\mathrm{NEMO}^{\mathrm{LPC}-\mathrm{KO}} / \mathrm{Tnf}^{-/-}$mice at the age of 1 year or more. Macroscopic and histological analysis of livers from $\mathrm{NEMO}^{\mathrm{LPC}-\mathrm{KO}} / \mathrm{Tnf}^{-1-}$ mice at the age between 50 and 63 weeks of age revealed that all mice $(n=12)$ developed HCC (Figure 2d). Collectively, these results demonstrated that TNF is not an essential trigger for spontaneous hepatocyte apoptosis and the development of hepatitis and HCC in NEMO ${ }^{\mathrm{LPC}-\mathrm{KO}}$ mice.

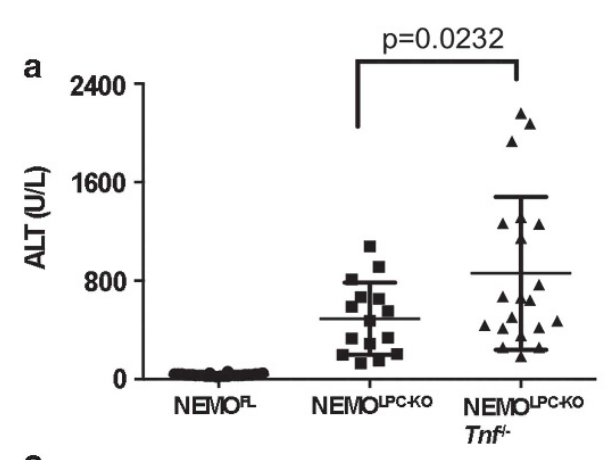

b

NEMOLPC-KO/ Tnfl-(8w)
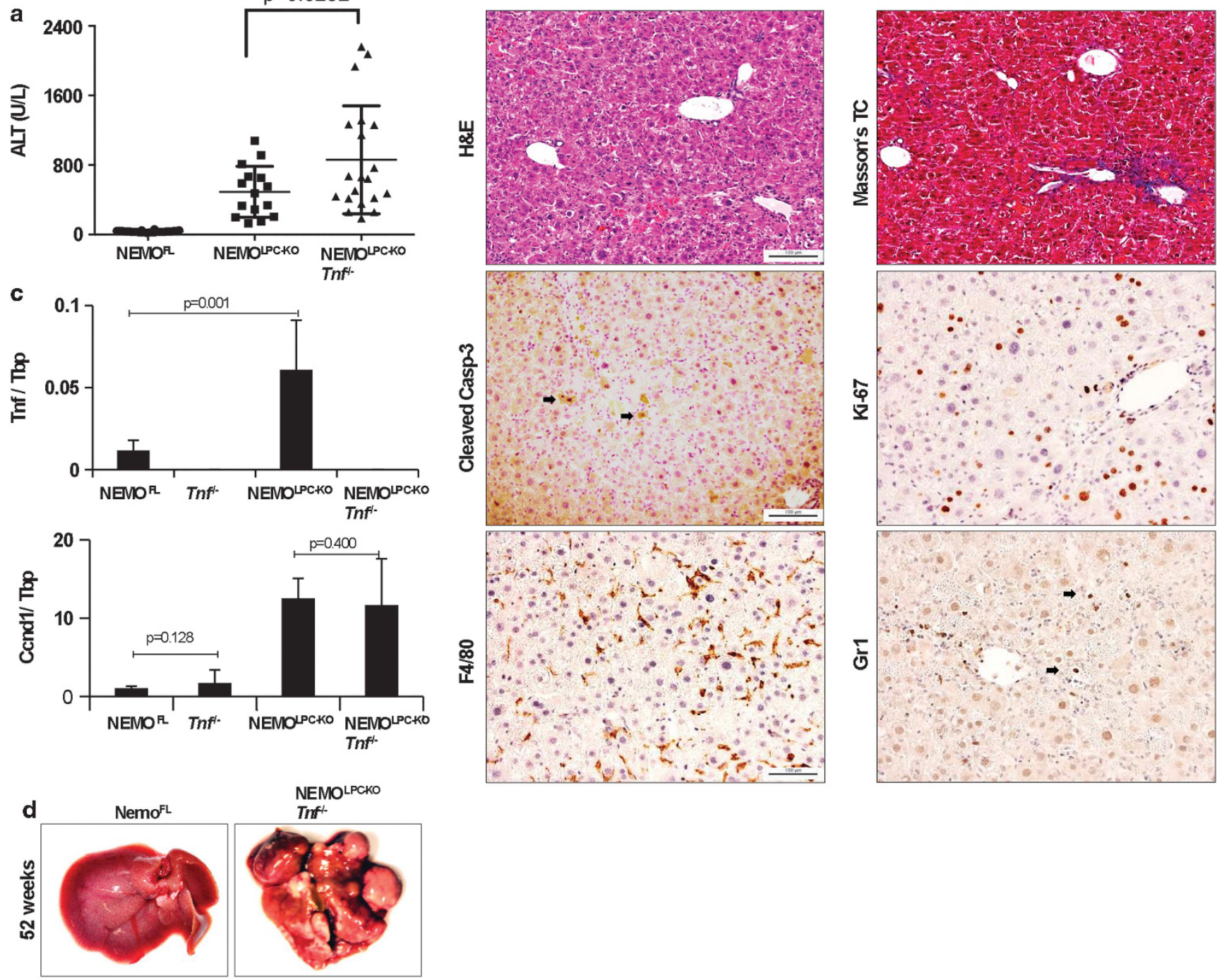

Figure 2 TNF deficiency does not prevent hepatocyte death, liver damage and HCC development in NEMO ${ }^{\text {LPC-KO }}$ mice. (a) Serum ALT levels in 8-week-old mice. (b) Liver sections of 8-week-old NEMO $\mathrm{LPC}^{\mathrm{KO}} / \mathrm{Tnf}^{-1-}$ mice stained with H\&E, Masson's Trichrome and for cleaved caspase-3 (indicated by arrows), Ki-67, F4/80 and Lys6G/ Gr1 (indicated by arrows). (c) qRT-PCR analysis of mRNA isolated from total liver tissue of 8-week-old mice ( $n=5$ per genotype, expression normalized to Tbp). (d) Macroscopic liver pictures of 1-year-old $\mathrm{NEMO}{ }^{\mathrm{FL}}$ and $\mathrm{NEMO} \mathrm{LPC}^{\mathrm{KO}} / \mathrm{Tnf}^{-1}$ - mice 
LPC-specific ablation of TNFR1, TRAIL-R or FAS does not prevent spontaneous hepatocyte death and liver inflammation in NEMO ${ }^{\mathrm{LPC}-\mathrm{KO}}$ mice. In addition to TNF, Fas ligand (FasL) and TRAIL can also induce FADD/ caspase-8-mediated apoptosis. FasL and TRAIL and their receptors are expressed in NEMO-deficient livers, with TRAIL-R being strongly upregulated, suggesting that they might be involved in mediating apoptosis in hepatocytes lacking NEMO (Figure 3a). To address the role of individual death receptors, but also potential functional redundancies, we used mice carrying loxP-flanked alleles of TNFR1, Fas and TRAIL-R to generate NEMO ${ }^{\mathrm{LPC}-\mathrm{KO}}$ mice that lack each of these receptors alone or with combined deficiency of all three death receptors specifically in LPCs (the triple TNFR1, Fas, TRAIL-R LPC-specific knockout is denoted hereafter as $3 \mathrm{DR}^{\mathrm{LPC}-\mathrm{KO}}$ for simplicity). Liver-specific deletion was confirmed by PCR genotyping (Figure $3 b$ ). As we could not detect TNFR1 or TRAIL-R expression in wild-type or NEMOdeficient hepatocytes using FACS or immunoblotting, we performed quantitative real-time PCR to confirm the deletion efficiency for these receptors in genomic DNA from total livers or from isolated hepatocytes. We found efficient deletion of both TNFR1 and TRAIL-R in isolated hepatocytes, whereas in the whole liver the deletion efficiency was lower due to the presence of non-parenchymal cells that are not targeted by the Alfp-Cre transgene (Figure 3c). Consistent with efficient ablation of TNFR1, hepatocytes from $\mathrm{NEMO}^{\mathrm{LPC}-\mathrm{KO}} / 3 \mathrm{DR}^{\mathrm{LPC}-\mathrm{KO}}$ mice were protected from TNF-induced apoptosis in contrast to hepatocytes from $\mathrm{NEMO}^{\mathrm{LPC}-\mathrm{KO}}$ mice (Figures $3 \mathrm{~d}$ and e). Fas deletion efficiency was confirmed using FACS analysis of hepatocytes (Figure 3f), whereas deletion of NEMO was demonstrated by immunoblotting in hepatocyte lysates (Figure $3 \mathrm{~g}$ ). Collectively, these data demonstrate that Alfp-Cre expression efficiently deleted all four alleles in the livers of NEMO ${ }^{\mathrm{LPC}-\mathrm{KO}} / 3 \mathrm{DR} \mathrm{R}^{\mathrm{LPC}-\mathrm{KO}}$ mice (Figure $3 \mathrm{e}$ ).

To assess whether TNFR1-, Fas- or TRAIL-R-mediated apoptosis induces the spontaneous death of NEMO-deficient hepatocytes, we measured serum ALT levels in 8-week-old NEMO ${ }^{\text {LPC-KO }} /$ TNFR $^{\text {LPC-KO }}$ NEMO ${ }^{\text {LPC-KO} / T R A I L R ~}{ }^{\text {LPC-KO }}$ and $\mathrm{NEMO}^{\mathrm{LPC}-\mathrm{KO}} / \mathrm{FAS}^{\mathrm{LPC}-\mathrm{KO}}$ mice. These mice displayed elevated serum ALT levels that were comparable to those measured in NEMO ${ }^{\mathrm{LPC}-\mathrm{KO}}$ mice at this age, demonstrating that LPC-specific ablation of TNFR1 or Fas or TRAIL-R failed
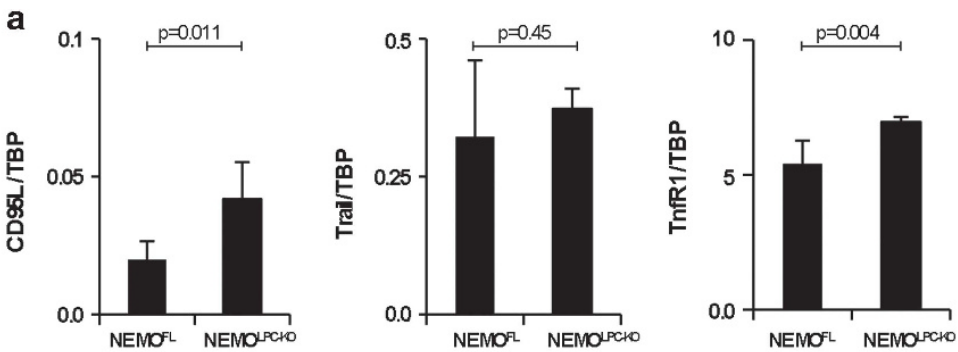

b

\begin{tabular}{|c|c|c|c|c|c|}
\hline \multicolumn{6}{|c|}{ Genomic DNA } \\
\hline & Liv & & & Tail & \\
\hline 1 & 2 & $\begin{array}{ll}3 & 4\end{array}$ & 1 & 2 & $\begin{array}{ll}34\end{array}$ \\
\hline
\end{tabular}
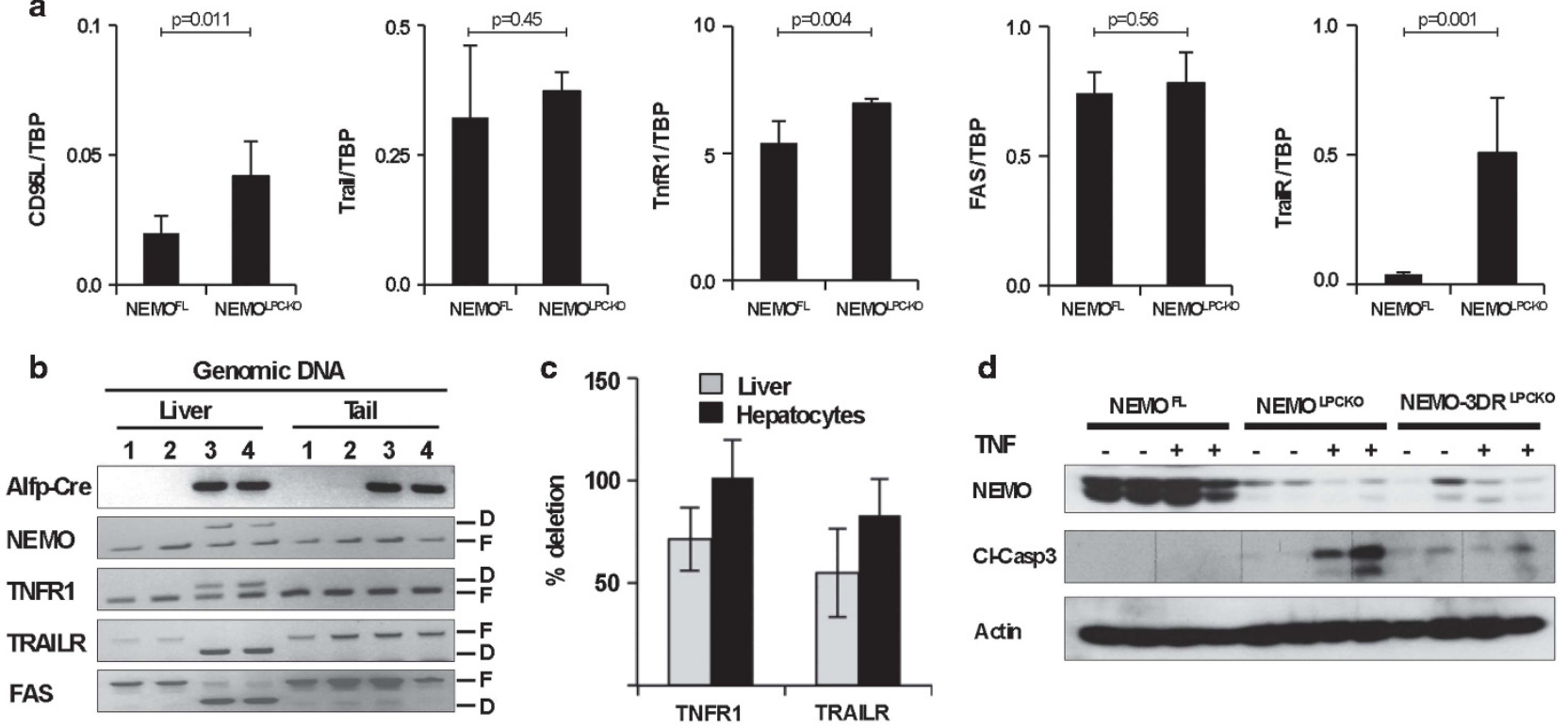

d
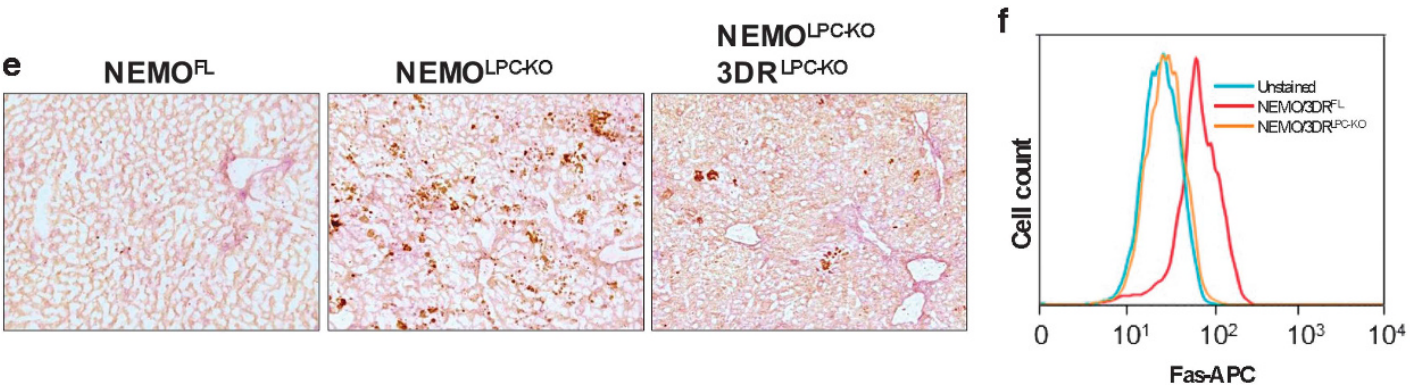

$\mathbf{g}$

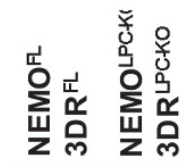

NEMO

Actin

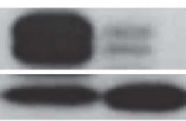

Figure 3 Validation and characterization of NEMO ${ }^{\mathrm{LPC}-K O} / 3 \mathrm{DR} \mathrm{LPC}^{\mathrm{LPO}}$ mice. (a) qRT-PCR analysis was performed using total liver RNA ( $n=5$ mice per genotype, expression normalized to Tbp). (b) PCR genotyping on genomic DNA isolated from total liver or tail tissue. F, floxed allele; D, deleted allele. (c) Graph showing deletion efficiency of TNFR1 and TRAIL-R measured using quantitative PCR analysis of genomic DNA from total liver tissue or isolated hepatocytes. (d and e) Immunoblot analysis of liver lysates with the indicated antibodies (d) and immunostainings of liver sections with antibodies recognizing cleaved caspase-3 (e) from NEMO ${ }^{\text {LPC-KO }}$ and NEMO-3DR ${ }^{\text {LPC-KO }}$ mice $5 \mathrm{~h}$ after TNF or PBS administration. (f) FACS analysis of surface Fas expression in hepatocytes isolated from mice with the indicated genotypes. (g) Immunoblot analysis of hepatocyte protein extracts from NEMO ${ }^{\mathrm{LPC}-\mathrm{KO}} / 3 \mathrm{DR} \mathrm{R}^{\mathrm{LPC}-\mathrm{KO}}$ and control showing deletion of NEMO in hepatocytes isolated from mice 
to prevent spontaneous liver damage in NEMO ${ }^{\mathrm{LPC}-\mathrm{KO}}$ mice (Figures $4 \mathrm{a}-\mathrm{c}$ ). To address potential functional redundancies between the three death receptors, we analysed $\mathrm{NEMO}^{\mathrm{LPC}-\mathrm{KO}}$ $3 R^{\mathrm{LPC}-K O}$ mice for liver damage at the age of 8 weeks and found that they exhibited elevated serum ALT levels comparable to $\mathrm{NEMO}^{\mathrm{LPC}-\mathrm{KO}}$ mice, demonstrating that even the lack of all three death receptors could not prevent spontaneous liver damage in NEMO ${ }^{\mathrm{LPC}-\mathrm{KO}}$ mice (Figure $4 \mathrm{~d}$ ). Macroscopically, the livers of 8-week-old NEMO ${ }^{\mathrm{LPC}-\mathrm{KO}}$ and $\mathrm{NEMO}^{\mathrm{LPC}-\mathrm{KO}} / 3 \mathrm{DR}^{\mathrm{LPC}-\mathrm{KO}}$ mice looked indistinguishable (Figure 4e). Histological analysis of liver sections from 8-week-old mice confirmed that LPC-specific ablation of the three death receptors could not prevent spontaneous hepatocyte apoptosis in NEMO ${ }^{\mathrm{LPC}-\mathrm{KO}}$ mice (Figure $4 \mathrm{~g}$ and Supplementary Figure S2C). Moreover, Ki-67 staining of liver sections and quantification of Ki-67-positive cells revealed similarly increased hepatocyte proliferation in the livers of $\mathrm{NEMO}^{\mathrm{LPC}-\mathrm{KO}} / 3 \mathrm{BR}^{\mathrm{LPC}-\mathrm{KO}}$ compared with NEMO ${ }^{\mathrm{LPC}-\mathrm{KO}}$ mice (Figure $4 \mathrm{~g}$ and Supplementary Figure S2D). Consistent with these findings, CyclinD1 mRNA expression was similarly increased in the liver of $\mathrm{NEMO} \mathrm{LPC}-\mathrm{KO}_{/ 3 D R^{\mathrm{LPC}-\mathrm{KO}} \text { and }}$ NEMO ${ }^{\mathrm{LPC}-\mathrm{KO}}$ mice (Figure $4 \mathrm{f}$ ). Furthermore, immunostaining for macrophages and granulocytes revealed similar numbers and distribution of myeloid cells in the liver of NEMO ${ }^{\mathrm{LPC}-\mathrm{KO}}$, $3 \mathrm{DR}^{\mathrm{LPC}-\mathrm{KO}}$ and NEMO ${ }^{\mathrm{LPC}-\mathrm{KO}}$ mice (Figure $4 \mathrm{~g}$ ). In addition, TNF mRNA expression did not differ significantly between NEMO ${ }^{\mathrm{LPC}-K O}$ and NEMO/3DR ${ }^{\mathrm{LPC}-\mathrm{KO}}$ mice (Figure 4f). Expression of AFP, a molecular marker of fetal hepatoblasts and adult hepatic stem cells, was comparable between $\mathrm{NEMO}^{\mathrm{LPC}-K O} / 3 \mathrm{RR}^{\mathrm{LPC}-\mathrm{KO}}$ and NEMO ${ }^{\mathrm{LPC}-\mathrm{KO}}$ mice (Figure $4 \mathrm{f}$ ). However, NEMO ${ }^{\mathrm{LPC}-\mathrm{KO}} / 3 \mathrm{DR}^{\mathrm{LPC}-\mathrm{KO}}$ mice showed reduced numbers of CK19-positive cells in the liver compared with NEMO ${ }^{\mathrm{LPC}-\mathrm{KO}}$ suggesting that death receptor deficiency ameliorated oval cell expansion (Supplementary Figure S2). Collectively, these results demonstrated that LPC-specific ablation of the three death receptors, TNFR1, Fas and TRAIL-R, could not prevent spontaneous hepatocyte apoptosis, compensatory proliferation and inflammation in the liver of NEMO ${ }^{\mathrm{LPC}-\mathrm{KO}}$ mice, showing that death receptors are not the inducers of hepatocyte apoptosis and hepatitis in these mice. These findings are surprising and show that death receptor-independent pathways induce spontaneous FADD-dependent apoptosis of NEMO-deficient hepatocytes.

NEMO deficiency strongly sensitizes hepatocytes to death induced by LPS administration. ${ }^{15}$ Similarly to the spontaneous apoptosis also LPS-induced apoptosis of NEMO-deficient hepatocytes depends on FADD expression. ${ }^{15}$ Prompted by the surprising failure of the triple death receptor knockout to prevent spontaneous hepatocyte apoptosis in NEMO ${ }^{\mathrm{LPC}-\mathrm{KO}}$ mice, we wanted to assess whether death receptor expression is required for LPS-induced liver damage in these mice. We therefore injected NEMO ${ }^{\mathrm{LPC}-K O} / 3 \mathrm{DR}^{\mathrm{LPC}-\mathrm{KO}}, \mathrm{NEMO}^{\mathrm{LPC}-\mathrm{KO}}$ and control mice with a sublethal dose of LPS and examined liver damage after $10 \mathrm{~h}$ by measurement of serum ALT levels and histological analysis of liver sections. As shown previously, LPS administration induced massive liver damage in NEMO ${ }^{\mathrm{LPC}-\mathrm{KO}}$ mice, as illustrated by ALT levels above $20000 \mathrm{U} / \mathrm{l}$ and strongly increased numbers of apoptotic hepatocytes (Figures $5 \mathrm{a}$ and b). Importantly, NEMO ${ }^{\mathrm{LPC}-\mathrm{KO}}$ / $3 \mathrm{R}^{\mathrm{LPC}-\mathrm{KO}}$ mice were protected from LPS-induced liver damage demonstrating that LPS-mediated apoptosis of NEMO-deficient hepatocytes is induced by death receptors, in contrast to the spontaneous hepatocyte death observed in NEMO ${ }^{\mathrm{LC}-\mathrm{KO}}$ mice that is death receptor-independent.

TNFR1-, TRAIL-R- and FAS-independent liver carcinogenesis in NEMO ${ }^{\mathrm{LPC}-\mathrm{KO}}$ mice. The results from the analysis of 8-week-old mice showed that TNFR1, TRAIL-R and Fas expression in LPCs is not required for the spontaneous death of hepatocytes and the development of hepatitis in NEMO ${ }^{\mathrm{LPC}-\mathrm{KO}}$ mice. To assess whether death receptors are implicated in the development of $\mathrm{HCC}$ in this model, we examined the livers of $\mathrm{NEMO} \mathrm{LPC}^{\mathrm{LPO}} / \mathrm{TNFR} 1^{\mathrm{LPC}-\mathrm{KO}}$, NEMO ${ }^{\text {LPC-KO} / T R A I L R ~} R^{\text {LPC-KO }}$, NEMO $^{\text {LPC-KO}} / F_{A S}{ }^{\text {LPC-KO }}$ and $\mathrm{NEMO}^{\mathrm{LPC}-K O} / 3 \mathrm{DR} \mathrm{R}^{\mathrm{LPC}-\mathrm{KO}}$ mice at the age of 1 year. All mouse lines exhibited elevated serum ALT levels at the age of 1 year, with NEMO ${ }^{\mathrm{LPC}-\mathrm{KO}} / \mathrm{TRAILR}^{\mathrm{LPC}-\mathrm{KO}}$ and NEMO ${ }^{\mathrm{LPC}-\mathrm{KO}} / \mathrm{FAS}^{\mathrm{LPC}-\mathrm{KO}}$ showing higher ALT levels compared with the NEMOLPC-KO mice (Figure 6b). Macroscopic and microscopic assessments of livers from mice at the age of 1 year revealed that NEMO ${ }^{\mathrm{LPC}-K O} / \mathrm{TNFR}^{\mathrm{LPC}-K O}, \mathrm{NEMO}{ }^{\mathrm{LPC}-\mathrm{KO}}$ / TRAILR ${ }^{\mathrm{LPC}-\mathrm{KO}}, \mathrm{NEMO} \mathrm{LPC}^{\mathrm{LOO}} / \mathrm{FAS} \mathrm{SPC}^{\mathrm{LPO}}$ and NEMO ${ }^{\mathrm{LPC}-K O}$ / 3DR ${ }^{\mathrm{LPC}-K O}$ mice developed HCC (Figure 6a). Macroscopic and microscopic quantifications did not reveal significant differences in the number or size of tumours found in the livers of NEMO ${ }^{\text {LPC-KO} / T N F R ~} 1^{\text {LPC-KO }}$, NEMO ${ }^{\text {LPC-KO/ }}$ TRAILR ${ }^{\text {LPC-KO }}, \mathrm{NEMO}^{\mathrm{LPC}-K O} / \mathrm{FAS}^{\mathrm{LPC}-\mathrm{KO}}$ and NEMO ${ }^{\mathrm{LPC}-\mathrm{KO}}$ / $3 R^{\text {LPC-KO }}$ mice compared with NEMO ${ }^{\text {LPC-KO }}$ mice (Figures $6 c-e$ and Supplementary Figure S1). Taken together, these results demonstrate that signalling by the three main death receptors, namely TNFR1, Fas and TRAIL-R, in LPCs is not required for spontaneous hepatocyte apoptosis, chronic hepatitis and HCC development in NEMO ${ }^{\mathrm{LPC}-\mathrm{KO}}$ mice.

NK cells and $T$ and $B$ lymphocytes are not required for the spontaneous development of hepatitis in NEMO ${ }^{\text {LPC-KO }}$ mice. NK cells have been implicated in inducing liver damage in NEMO ${ }^{\mathrm{LPC}-\mathrm{KO}}$ mice. $^{24}$ To address the role of NK cells in the development of hepatitis in NEMO ${ }^{\mathrm{LPC}-\mathrm{KO}}$ mice, we performed immunodepletion with anti-Asialo GM1 $(\alpha$-ASGM1) antibodies in vivo (Figure 7a). As shown in Figure $7 b$, after four consecutive $\alpha$-ASGM1 antibody injections NK cells were efficiently depleted from the spleen and liver. However, analysis of serum ALT levels and also immunohistological analysis of liver sections obtained from the mice at the end of the experiment revealed that NK cell depletion did not prevent apoptosis and compensatory proliferation of hepatocytes, oval cell activation and inflammation (Figure 7c and Supplementary Figure S3). Thus, NK cells are not required for spontaneous hepatitis development in $\mathrm{NEMO}^{\mathrm{LPC}-\mathrm{KO}}$ mice.

Cells of the adaptive immune system and in particular $\mathrm{T}$ cells are implicated in inducing liver damage in different models of hepatitis but also in human patients. We therefore addressed the role of $\mathrm{B}$ and $\mathrm{T}$ lymphocytes in NEMO ${ }^{\mathrm{LPC}-\mathrm{KO}}$ mice by crossing them to Rag $1^{-1-}$ mice. Analysis of serum ALT levels and immunohistological examination of livers from 8-week-old $\mathrm{NEMO}{ }^{\mathrm{LPC}-\mathrm{KO}} / \operatorname{Rag}^{-1-}$ mice revealed that the absence of $\mathrm{B}$ and $\mathrm{T}$ cells did not protect $\mathrm{NEMO} \mathrm{LPC}^{\mathrm{LPO}}$ mice from hepatocyte apoptosis and liver inflammation (Figure $7 d$ ). 

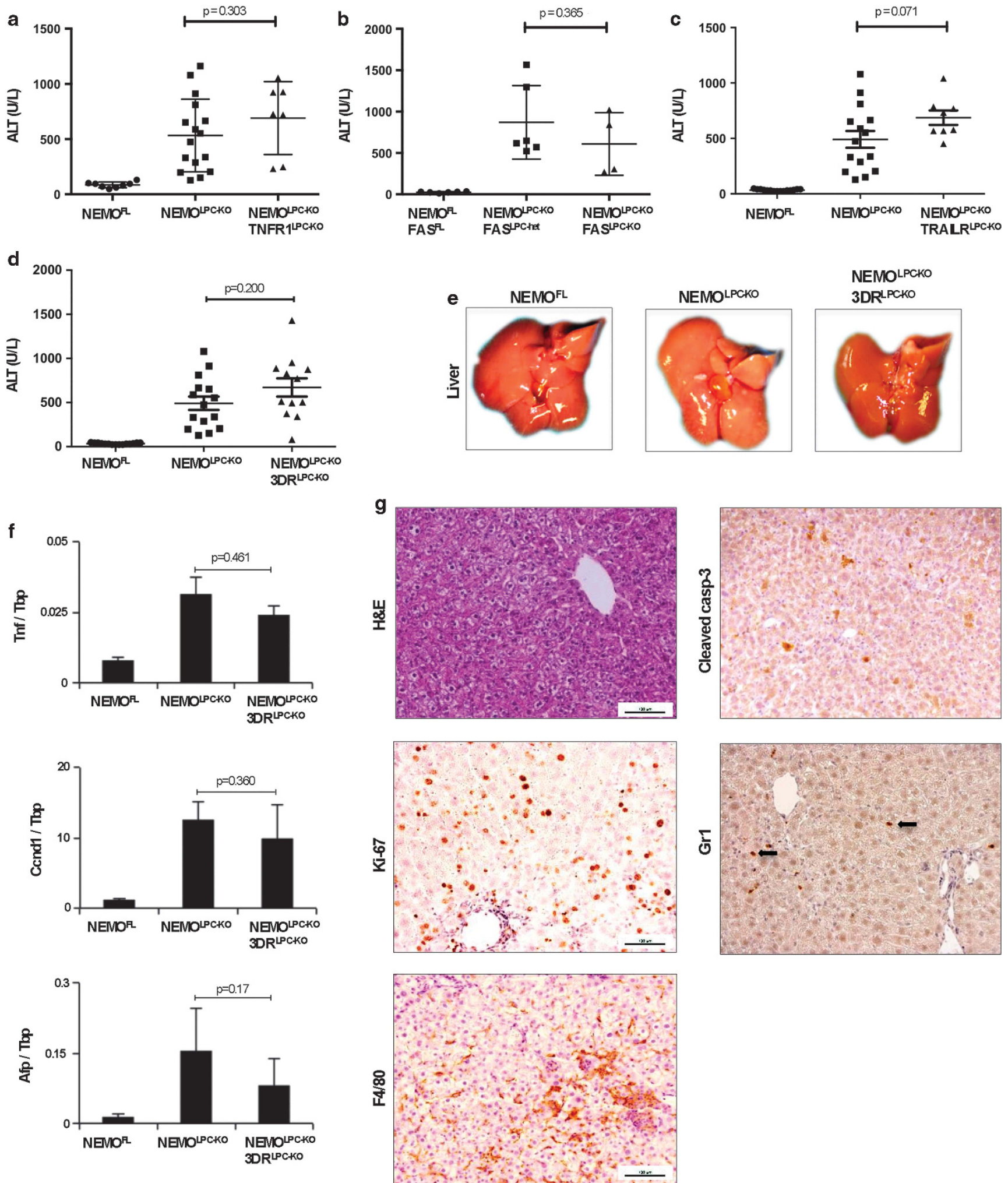

Figure 4 Individual or combined LPC-specific ablation of TNFR1, FAS and TRAIL-R does not prevent hepatocyte death or inflammation in NEMOLPC-KO mice. (a-d) Serum ALT levels in 8-week-old mice with the indicated genotypes. (e) Representative pictures of livers from 8-week-old mice with the indicated genotypes. (f) qRT-PCR analysis of $\mathrm{mRNA}$ isolated from total liver tissue of 8-week-old mice ( $n=5$ mice per genotype, expression normalized to Tbp). (g) Liver sections from 8-week-old NEMO LPC-KO, $3 \mathrm{DR} \mathrm{LPC}^{\mathrm{LPO}}$ mice were stained with H\&E or for cleaved caspase-3, Ki-67, F4/80, Lys6G/Gr1 (indicated by arrows) 


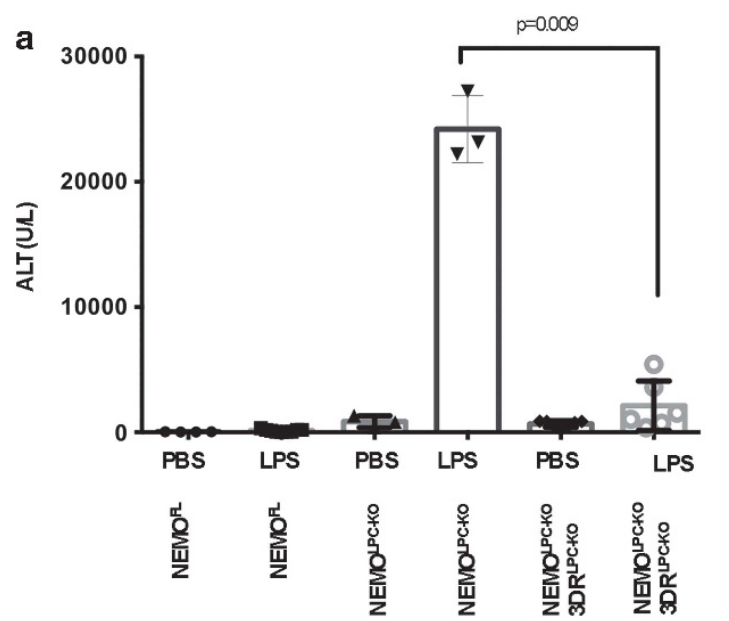

b

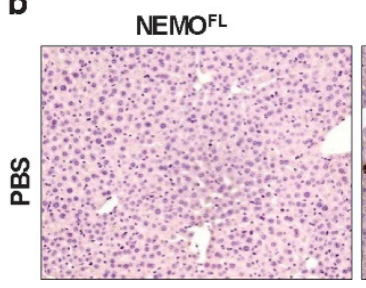

NEMOLPCKO
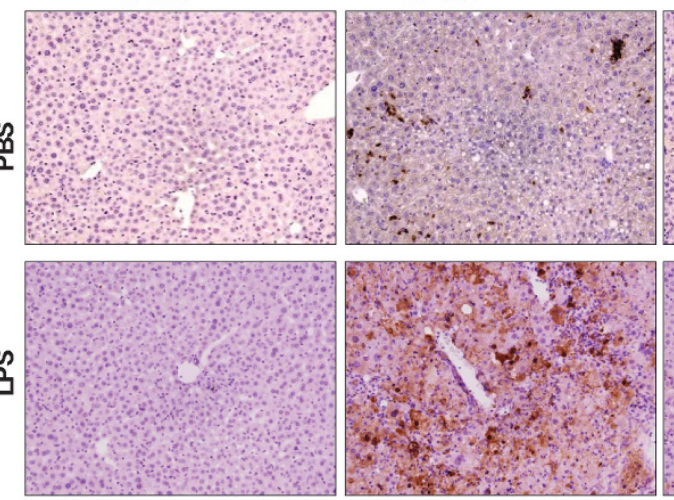

NEMOLPCKO 3DR ${ }^{\mathrm{PCKKO}}$
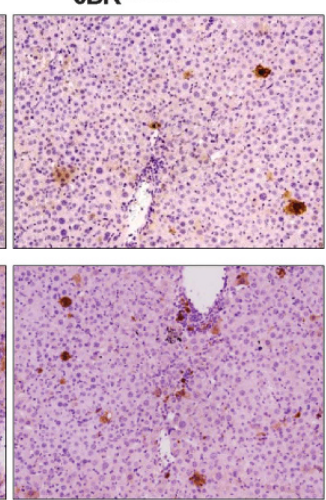

Figure $5 \mathrm{NEMO} \mathrm{LPC}^{\mathrm{LCO}} / 3 \mathrm{BDR} \mathrm{R}^{\mathrm{LPC}-\mathrm{KO}}$ mice are protected from LPS-mediated toxicity. (a) Serum ALT levels measured $10 \mathrm{~h}$ after LPS or PBS administration in mice with the indicated genotypes. (b) Representative images of liver sections from PBS- or LPS-injected mice with the indicated genotypes immunostained for cleaved caspase-3

Moreover, macroscopic and histological examination of livers from 42-week-old animals revealed that NEMO ${ }^{\mathrm{LPC}-\mathrm{KO}}$ Rag $1^{-1-}$ mice developed liver tumours similarly to their NEMO ${ }^{\mathrm{LPC}-\mathrm{KO}} /$ Rag 1 $^{+/-}$littermates (Figure 7e). Therefore, B and $\mathrm{T}$ lymphocytes are dispensable for the development of hepatitis and liver tumours in NEMO ${ }^{\mathrm{LPC}-\mathrm{KO}}$ mice.

\section{Discussion}

Signalling pathways activated downstream of death receptors, such as TNFR1, regulate cell death and inflammation and have been implicated in the pathogenesis of acute and chronic liver diseases and in liver carcinogenesis. ${ }^{25,26}$ Studies in knockout mice lacking $\mathrm{NF}-\kappa \mathrm{B}$ signalling components revealed an essential role of $\mathrm{NF}-\kappa \mathrm{B}$ in protecting the fetal liver from TNF-induced cell death. ${ }^{21,22}$ We therefore hypothesized that the spontaneous apoptosis of NEMO-deficient hepatocytes that results in chronic hepatitis and HCC development in NEMO ${ }^{\mathrm{LPC}-\mathrm{KO}}$ mice is driven by death receptor signalling. ${ }^{27}$

Consistent with our earlier results showing that FADD deficiency could prevent spontaneous and LPS/TNF-induced apoptosis of NEMO-deficient hepatocytes, ${ }^{15}$ we show here that LPC-specific ablation of FADD also prevents HCC development in $\mathrm{NEMO}^{\mathrm{LPC}-\mathrm{KO}}$ mice demonstrating that FADD-dependent hepatocyte apoptosis is essential for hepatocarcinogenesis in this model. In addition, LPC-specific knockout of caspase-8 could prevent hepatocyte apoptosis and HCC development in NEMO ${ }^{\text {LPC-KO }}$ mice. ${ }^{28}$ However, whereas caspase-8 deficiency caused massive necrotic hepatocyte death in NEMO ${ }^{\mathrm{LPC}-\mathrm{KO}}$ mice resulting in severe cholestatic liver disease, ${ }^{28}$ we found that FADD deficiency caused only very mild focal hepatocyte necrosis without any signs of biliary damage and cholestasis. This difference could reflect different functions of FADD and caspase-8 in regulating necrotic hepatocyte death, or alternatively a different health status of the mice considering that commensal or opportunistic microorganisms could be involved in triggering necrosis of hepatocytes.
On the basis of the well-established role of FADD and caspase-8 as mediators of death receptor-induced apoptosis, we were surprised that our extensive genetic studies failed to confirm an important role of death receptor signalling in triggering hepatocyte apoptosis, chronic hepatitis and HCC in NEMO ${ }^{\mathrm{LC}-\mathrm{KO}}$ mice. First, we found that conventional knockout of TNF or conditional LPC-specific individual ablation of TNFR1, Fas or TRAIL-R did not prevent liver damage and $\mathrm{HCC}$ in NEMO ${ }^{\mathrm{LPC}-K O}$ mice. Then, to address potential functional redundancies between the three death receptors we generated NEMO ${ }^{\text {LPC-KO }}$ mice with combined LPC-specific deficiency of the three death receptors and found that even their simultaneous absence could not prevent spontaneous hepatocyte apoptosis, chronic hepatitis and HCC in NEMO ${ }^{\mathrm{PC}-\mathrm{KO}}$ mice. In contrast, triple death receptor deficiency could protect NEMOLPC-KO mice from LPS-induced liver injury, showing that different mechanisms trigger LPS-induced and spontaneous hepatocyte apoptosis in NEMO ${ }^{\text {LPC-KO }}$ mice.

An earlier study suggested that NK cells acting via TRAIL-R mediate hepatocyte apoptosis in NEMO ${ }^{\mathrm{LPC}-\mathrm{KO}}$ mice. ${ }^{24}$ Our results do not support a role for NK cells or TRAIL-R in mediating spontaneous hepatocyte apoptosis, hepatitis and HCC in NEMO ${ }^{\text {LPC-KO }}$ mice. Consistent with our results using LPC-specific TRAIL-R knockout, a recent study showed that systemic TRAIL-R deficiency could not prevent hepatocyte apoptosis, hepatitis and HCC in NEMO ${ }^{\mathrm{LPC}-\mathrm{KO}}$ mice. ${ }^{29}$ In the same study, systemic TNFR1 deficiency could significantly protect NEMOLPC-KO mice from hepatocyte apoptosis and compensatory proliferation, liver inflammation and fibrosis, and also inhibited liver tumour progression. It is therefore surprising that LPC-specific knockout of TNFR1, and even in combination with Fas and TRAIL-R, failed to protect NEMO ${ }^{\mathrm{LC}-K O}$ mice from hepatocyte death, hepatitis and HCC development. Considering that haematopoietic chimera experiments suggested that TNFR1 deficiency in radioresistant cells prevents hepatitis and $\mathrm{HCC}$ in NEMO ${ }^{\mathrm{LPC}-\mathrm{KO}}$ mice, ${ }^{29}$ one possibility is that TNFR1 acts in liver stromal cells that are not targeted by the Alfp-Cre transgene, such as 
a
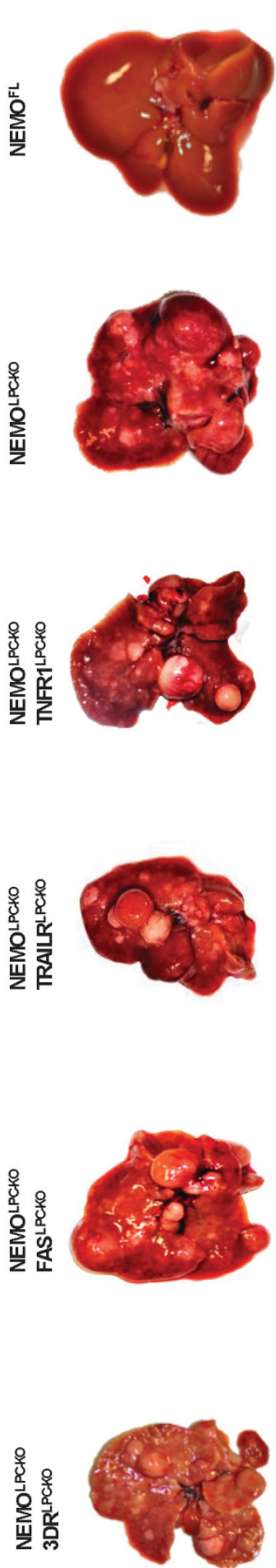

H\&E
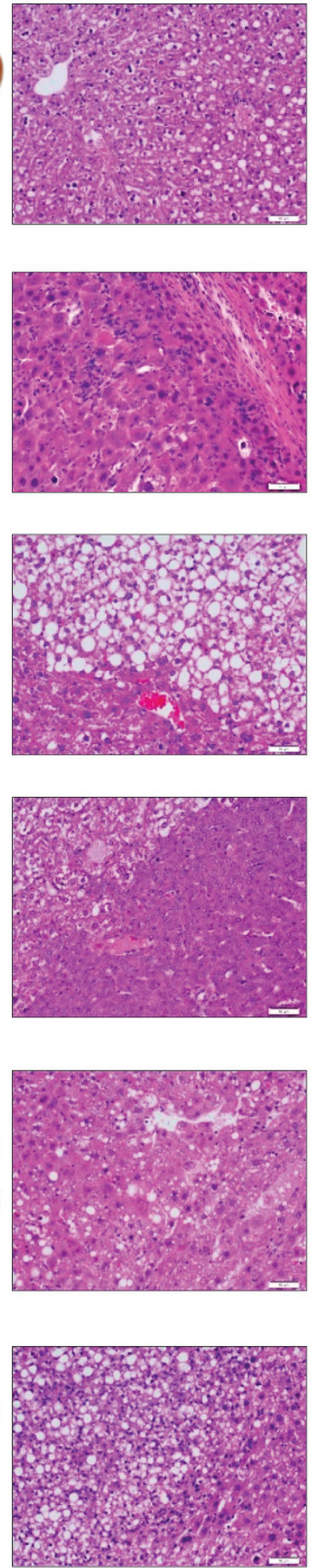

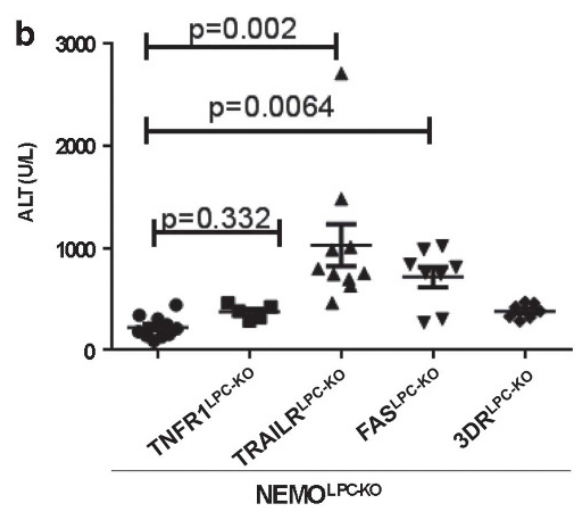

C

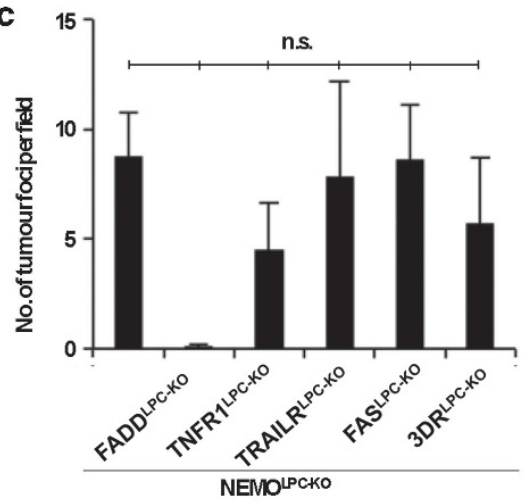

d
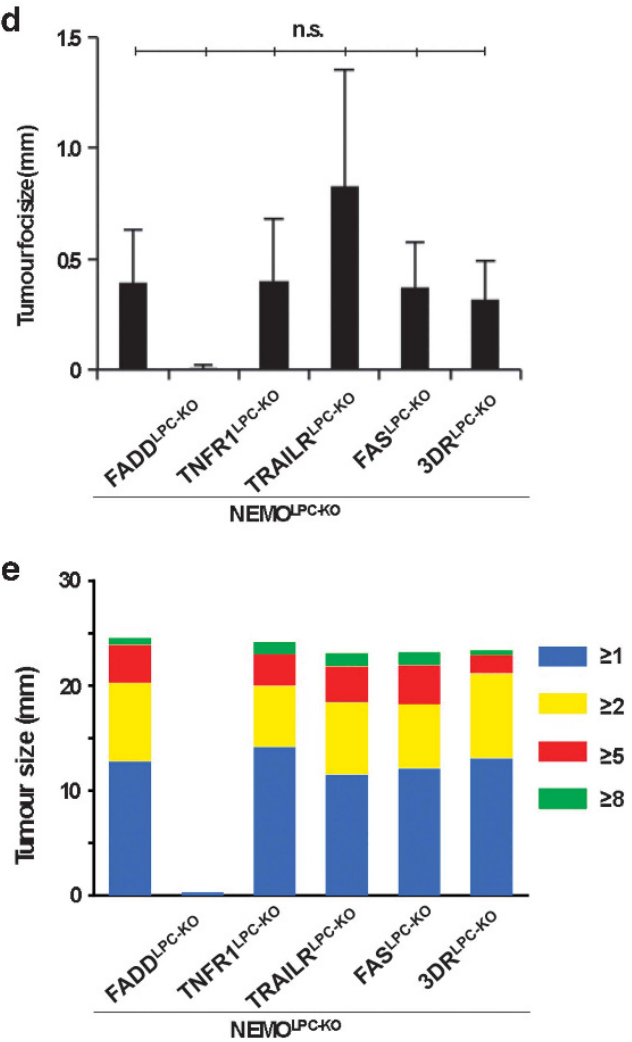

Figure 6 Individual or combined LPC-specific ablation of TNFR1, FAS and TRAIL-R does not prevent HCC development in NEMO ${ }^{\text {LPC-KO }}$ mice. (a) Macroscopic images of livers from 1-year-old mice with the indicated genotypes and corresponding H\&E-stained images of liver sections. (b) Serum ALT values of 1-year-old mice. (c) Graph showing number of dysplastic/tumour foci per liver section in 1-year-old mice. (d) Graph showing size of tumour foci determined microscopically in liver sections. (e) Graph showing size of tumours in 1-year-old mice counted and classified into groups based on the analysis of macroscopic liver images 
a

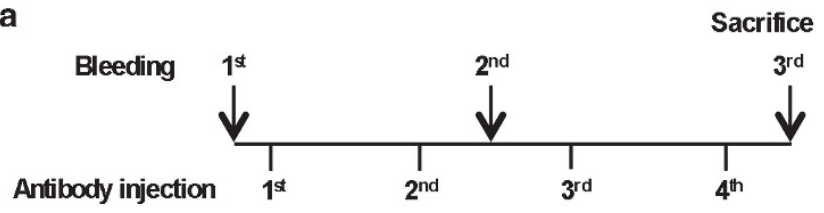

b
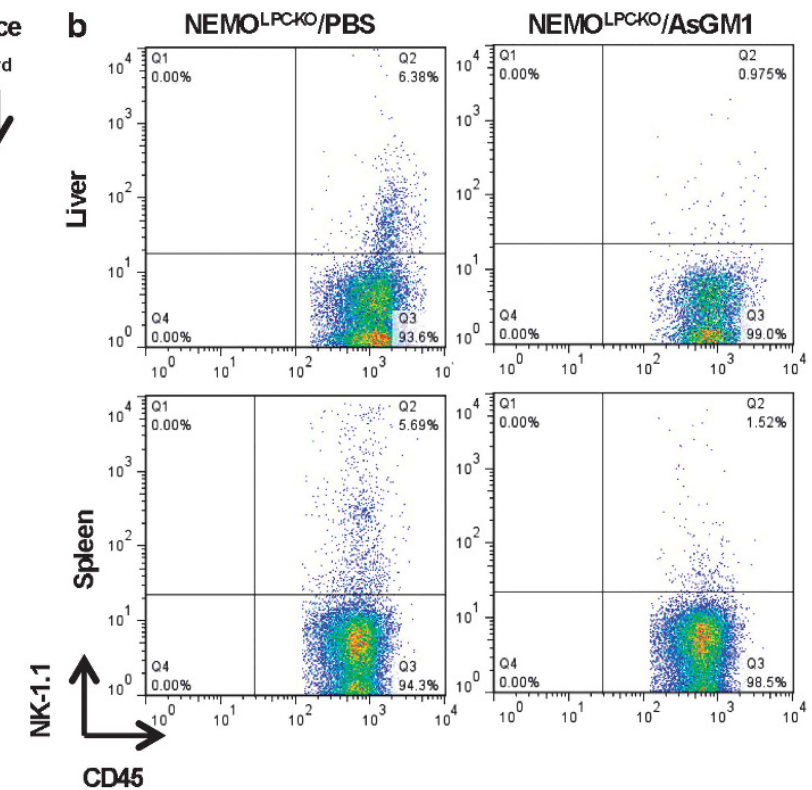
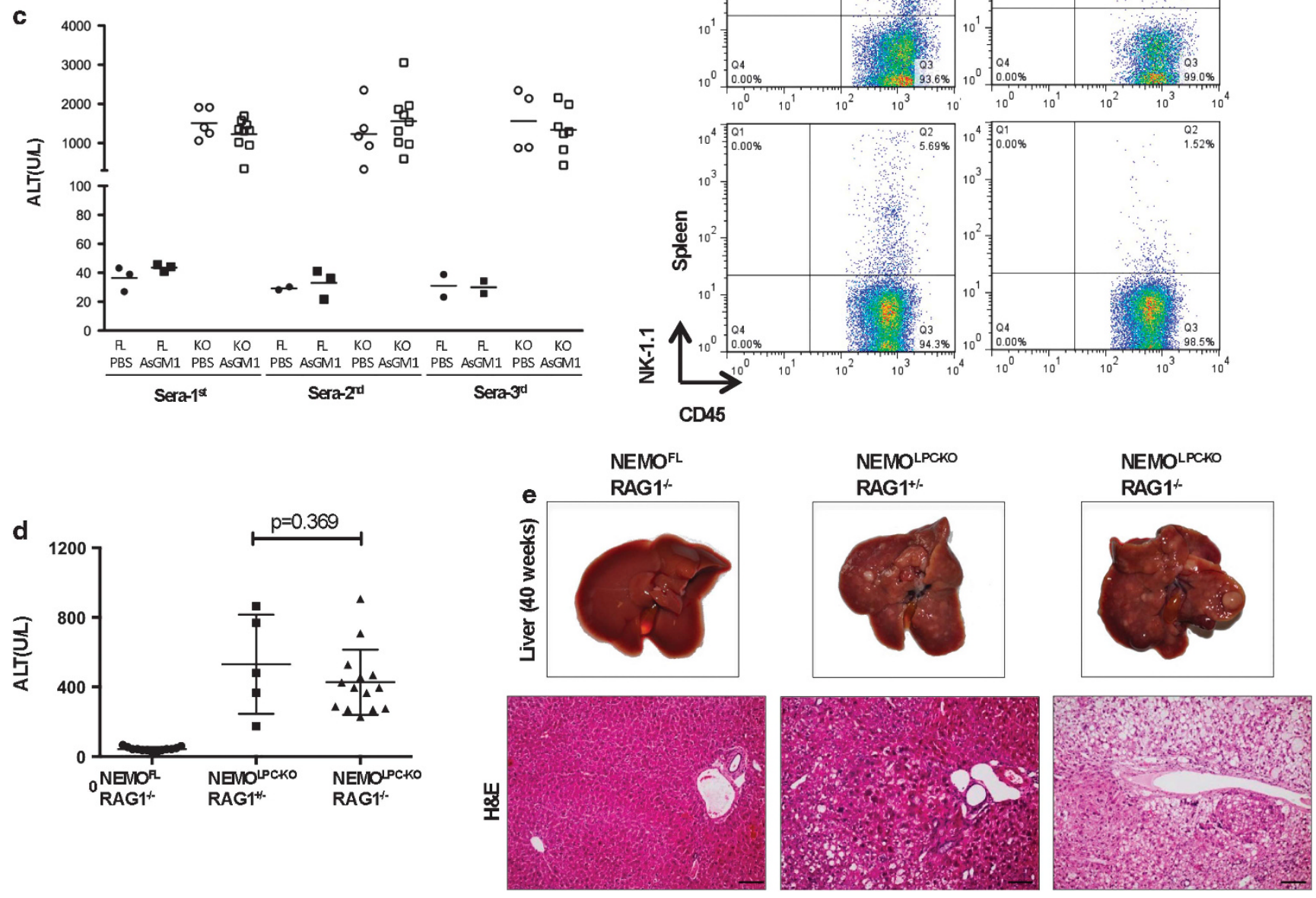

Figure 7 T, B and NK cells are dispensable for the induction of liver pathology in NEMO ${ }^{\mathrm{LPC}-K O}$ mice. (a) Experimental scheme for depleting NK cells in NEMO ${ }^{\mathrm{LPC}-\mathrm{KO}}$ mice. (b) FACS plots of immune cells isolated from the liver and spleen of mice injected with PBS or anti-AsialoGM1 antibody. (c) Serum ALT levels measured at three different time points; before depletion, intermittently after two rounds of AsialoGM1 antibody administrations, and finally after killing. (d) Serum ALT levels measured in 8-week-old

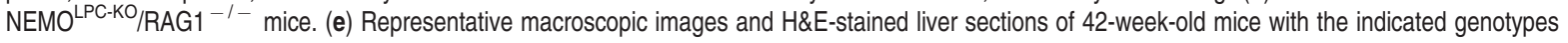

stellate cells or endothelial cells to mediate hepatocyte apoptosis and liver tumour progression. However, in that case TNFR1 signalling must be driven by a ligand other than TNF as TNF deficiency failed to prevent or ameliorate liver damage and HCC development in NEMO ${ }^{\mathrm{LPC}-\mathrm{KO}}$ mice.

In conclusion, our experiments demonstrated that TNFR1, Fas and TRAIL-R signalling in LPCs is dispensable for spontaneous hepatocyte apoptosis, chronic hepatitis and HCC development in NEMO ${ }^{\mathrm{LPC}-\mathrm{KO}}$ mice. These findings are surprising and raise questions as to which upstream pathway(s) trigger(s) FADD/caspase-8-dependent apoptosis of NEMO-deficient hepatocytes. In addition to TNFR1, Fas and TRAIL-R, DR3 is another death receptor capable of inducing NF- $\kappa$ B activation and FADD/caspase-8-dependent apoptosis upon stimulation with its ligand TL1A. ${ }^{16,30}$ However, DR3 is mainly expressed in $\mathrm{T}$ cells and has not been reported to function in hepatocytes, and we did not detect upregulation of its expression in the NEMO-deficient liver suggesting that DR3 is not involved in driving hepatocyte apoptosis in NEMO ${ }^{\text {LC-KO }}$ mice. Together, our results suggest that as yet unidentified death receptor, NK cell and B- and T-cell-independent mechanisms trigger the spontaneous FADD/caspase-8-mediated apoptosis of NEMO-deficient hepatocytes. Further studies addressing how NEMO controls the activation of FADD/caspase-8-mediated apoptosis will be required to shed light on the mechanisms triggering spontaneous hepatitis and cancer in NEMO ${ }^{\mathrm{LPC}-\mathrm{KO}}$ mice and may be relevant for the pathogenesis of human chronic liver diseases and the development of HCC.

Materials and methods

Generation and handling of mice. The following mouse lines were used in this study: AlfpCre, ${ }^{31}$ NEMO floxed, ${ }^{10}$ FADD floxed, ${ }^{32}$ Tnf $^{-1-},{ }^{23}$ 
TNFR1 floxed, ${ }^{33}$ TRAIL-R floxed ${ }^{34}$ Fas floxed ${ }^{35}$ and $R a g 1^{-1-}-36$ All mice were maintained in C57BL/ 6 background. Animals were bred at the animal facility of the Institute for Genetics, University of Cologne, Germany. All animal procedures were conducted in accordance with European, national and institutional guidelines and protocols and were approved by local government authorities (Landesamt für Natur, Umwelt und Verbraucherschutz Nordrhein-Westfalen, Germany).

Quantitative real-time polymerase chain reaction (q-RT PCR). Isolation of total RNA and CDNA synthesis were performed as previously described. ${ }^{9}$ The gene-specific Taq Man assays were performed. mRNA expression was normalized to the expression of the housekeeping gene TBP. For the determination of deletion efficiency, genomic DNA both from isolated hepatocytes or whole-liver tissue samples was used to perform a SYBR Green $q-R T$ PCR. Deletion efficiency was calculated as the ratio of copies of the deleted product to that of the control PCR product.

Serum levels of alanine amino transferase. About $100 \mu \mathrm{l}$ of blood was collected either from the submandibular vein or from the caval vein during the final killing. ALT was measured using standard assays in a Roche-Cobas C111 biochemical analyser.

Hepatocyte and immune cell isolation from liver and spleen and FACS analysis. Primary hepatocytes were isolated by perfusing the liver via the caval vein with EBSS $+100 \mathrm{mM}$ EGTA followed by collagenase solution (EBSS $+15 \mathrm{mg}$ Collagenase $\mathrm{D}+2 \mathrm{mg}$ Trypsin inhibitor) at 37 degrees. The liver was gently scraped in DMEM $+1 \%$ FCS, filtered through $70-\mu \mathrm{m}$ nylon filter, mixed with equal volume of $80 \%$ Percoll/HBSS solution and spun at $200 \times g$ for $7 \mathrm{~min}$. Hepatocytes settled at the bottom were washed with PBS.

To determine the NK cell depletion efficiency using the anti-AsialoGM1 antibody, the liver and spleen immune cell populations were isolated and analysed using FACS. To isolate the immune cells from the spleen and liver, the tissues were mechanically dissociated in D-PBS using a syringe plunger, passed through a $70-\mu \mathrm{m}$ cell strainer, and centrifuged at 1500 r.p.m. for $5 \mathrm{~min}$. Liver immune cells were separated from hepatocytes by Percoll gradient centrifugation at $800 \times g$ for 20 min. Erythrocytes were lysed in $0.15 \mathrm{M} \mathrm{NH} 4 \mathrm{Cl}$, washed three times in D-PBS and diluted in Stain Buffer (FBS; BD, San Diego, CA, USA; 554656). The cells were pre-incubated with rat anti-mouse CD16/CD32 (Mouse Fc Block; BD, 553141) antibody for $10 \mathrm{~min}$, and then incubated with CD45 (BD, 553081) and NK1.1 (BD, 550627 ) antibodies for $30 \mathrm{~min}$ in the dark. After two washes, the cells were resuspended in PBS and analysed using a BD FACScalibur (BD Biosciences, San Jose, CA, USA), whereas the data were analysed using Windows Multiple Document Interface (WinMDI) 2.9 for Flow Cytometry. Surface expression of Fas in hepatocytes was analysed by FACS using PE-labelled hamster anti-mouse Fas antibody (BD Pharmingen, San Diego, CA, USA; cat. no. 554258).

LPS and TNF responses. Age- and sex-matched animals between 12- and 15-week old were injected intraperitoneally with $2.5 \mu \mathrm{g}$ of LPS (From Escherichia coli 0111:B4, Sigma-Aldrich, Munich, Germany; L2630) or $10 \mathrm{ng}$ recombinant murine TNF per gram of body weight. Animals were killed $10 \mathrm{~h}$ after LPS and $5 \mathrm{~h}$ after TNF administration, and blood and liver were collected for analysis.

Analysis of livers and immunohistochemistry. Livers were assessed macroscopically and photographed. In addition, tumour size (diameter), architecture and histology were determined using 5- $\mu$ m-thick sections of formalin-fixed $(\mathrm{O} / \mathrm{N})$, paraffin-embedded liver tissues stained with haematoxylin and eosin (H\&E). Fibrosis was determined with Masson's Trichrome staining. Immunohistochemical staining of sections was performed after antigen retrieval in Na-Citrate buffer with $0.005 \%$ tween and boiling in a pressure cooker for $20 \mathrm{~min}$. Antibodies used were active caspase-3 (R\&D Systems, Minneapolis, MN, USA; clone AF835), Ki-67 (Dako Cytomation, Glostrup, Denmark; M724901), F4/80 (home-made), Ly6G/Gr1 (BD, 551459) and CK19 (Developmental Studies Hybridoma Bank, lowa City, IA, USA; TROMA-III). Biotinylated secondary antibodies, Avidin/Biotin blocking kit (Vector Labs, Burlingame, CA, USA; SP-2001), HRP-conjugated biotin (ABC Elite Kit, Vector Labs, PK6100) and DAB substrate (Dako Cytomation; K3466) were used in all stainings. Immunostainings for cleaved Caspase-3 in livers from TNF-injected mice were performed on cryosections (Tissue-Tek, Sakura Finetek, Torrance, CA, USA; cat. no. 4583)
Immunoblotting. Tissue lysates were prepared by homogenizing liver tissue in buffer $(150 \mathrm{mM} \mathrm{NaCl}, 1 \% \mathrm{NP}-40,0.1 \%$ SDS in a $50 \mathrm{mM}$ Tris buffer at $\mathrm{pH} 7.5$ including the Protease inhibitor tablets (complete, Roche, Mannheim, Germany, 05892970001) and phosphatase inhibitors (PhosSTOP Roche, 04906837001). Immunodetection was performed using ECL reagent from GE Healthcare, Buckinghamshire, UK; RPN 2106). Antibodies used were as follows: anti-NEMO (homemade), ${ }^{15}$ anti-cleaved caspase-3 (Cell Signalling, Danvers, MA, USA 9661) and Actin (Santa Cruz Biotechnology, Santa Cruz, CA, USA; sc-1616).

Acknowledgements. MP acknowledges funding from the ERC (2012ADG_20120314), the DFG (SFB670, SFB829, SPP1656), the European Commission (FP7 grants 223404 (Masterswitch) and 223151 (InflaCare)), the Deutsche Krebshilfe (Grant 110302), the Else Kröner-Fresenius-Stiftung and the Helmholtz Alliance Preclinical Comprehensive Cancer Center. VK was supported by a Marie Curie Career Development Fellowship (FP7-PEOPLE-2010-IEF; Proposal No.: 275767).

1. Shariff MI, Cox IJ, Gomaa Al, Khan SA, Gedroyc W, Taylor-Robinson SD. Hepatocellular carcinoma: current trends in worldwide epidemiology, risk factors, diagnosis and therapeutics. Exp Rev Gastroenterol Hepatol 2009; 3: 353-367.

2. El-Serag HB. Hepatocellular carcinoma. N Engl J Med 2011; 365: 1118-1127.

3. Sun B, Karin M. Obesity, inflammation, and liver cancer. J Hepatol 2012; 56: 704-713.

4. Ben-Neriah Y, Karin M. Inflammation meets cancer, with NF-kappaB as the matchmaker. Nat Immunol 2011; 12: 715-723.

5. Hayden MS, Ghosh S. NF-kappaB, the first quarter-century: remarkable progress and outstanding questions. Genes Dev 2012; 26: 203-234.

6. Luedde T, Schwabe RF. NF-kappaB in the liver-linking injury, fibrosis and hepatocellular carcinoma. Nat Rev Gastroenterol Hepatol 2011; 8: 108-118.

7. Sun B, Karin M. NF-kappaB signaling, liver disease and hepatoprotective agents. Oncogene 2008; 27: 6228-6244.

8. Luedde T, Heinrichsdorff J, de Lorenzi R, De Vos R, Roskams T, Pasparakis M. IKK1 and IKK2 cooperate to maintain bile duct integrity in the liver. Proc Natl Acad Sci USA 2008; 105: 9733-9738.

9. Makris C, Godfrey VL, Krahn-Senftleben G, Takahashi T, Roberts JL, Schwarz T et al. Female mice heterozygous for IKK gamma/NEMO deficiencies develop a dermatopathy similar to the human $\mathrm{X}$-linked disorder incontinentia pigmenti. Mol Cell 2000; 5: 969-979.

10. Schmidt-Supprian M, Bloch W, Courtois G, Addicks K, Israel A, Rajewsky K et al. NEMO/IKK gamma-deficient mice model incontinentia pigmenti. Mol Cell 2000; 5: 981-992.

11. Rudolph D, Yeh W, Wakeham A, Rudolph B, Nallainathan D, Potter J et al. Severe liver degeneration and lack of NF-kappaB activation in NEMO/IKKgamma-deficient mice. Genes Dev 2000; 14: 854-862.

12. Pikarsky E, Porat RM, Stein I, Abramovitch R, Amit S, Kasem S et al. NF-kappaB functions as a tumour promoter in inflammation-associated cancer. Nature 2004; 431: 461-466.

13. Haybaeck J, Zeller N, Wolf MJ, Weber A, Wagner U, Kurrer MO et al. A lymphotoxin-driven pathway to hepatocellular carcinoma. Cancer Cell 2009; 16: 295-308.

14. Maeda S, Kamata H, Luo JL, Leffert H, Karin M. IKKbeta couples hepatocyte death to cytokine-driven compensatory proliferation that promotes chemical hepatocarcinogenesis. Cell 2005; 121: 977-990.

15. Luedde T, Beraza N, Kotsikoris V, van Loo G, Nenci A, De Vos R et al. Deletion of NEMO/IKKgamma in liver parenchymal cells causes steatohepatitis and hepatocellular carcinoma. Cancer cell 2007; 11: 119-132.

16. Ashkenazi A, Dixit VM. Death receptors: signaling and modulation. Science 1998; 281 1305-1308.

17. Liedtke C, Bangen JM, Freimuth J, Beraza N, Lambertz D, Cubero FJ et al. Loss of caspase- 8 protects mice against inflammation-related hepatocarcinogenesis but induces non-apoptotic liver injury. Gastroenterology 2011; 141: 2176-2187.

18. Bonnet MC, Preukschat D, Welz PS, van Loo G, Ermolaeva MA, Bloch W et al. The adaptor protein FADD protects epidermal keratinocytes from necroptosis in vivo and prevents skin inflammation. Immunity 2011; 35: 572-582.

19. Welz PS, Wullaert A, Vlantis K, Kondylis V, Fernandez-Majada V, Ermolaeva M et al. FADD prevents RIP3-mediated epithelial cell necrosis and chronic intestinal inflammation. Nature 2011; 477: 330-334.

20. Zhang H, Zhou X, McQuade T, Li J, Chan FK, Zhang J. Functional complementation between FADD and RIP1 in embryos and lymphocytes. Nature 2011; 471: 373-376.

21. Doi T, Marino M, Takahashi T, Yoshida T, Sakakura T, Old L et al. Absence of tumor necrosis factor rescues RelA-deficient mice from embryonic lethality. Proc Natl Acad Sci USA 1999; 96: 2994-2999.

22. Li $Q$, Van Antwerp D, Mercurio F, Lee KF, Verma IM. Severe liver degeneration in mice lacking the IkappaB kinase 2 gene. Science 1999; 284: 321-325. 
23. Pasparakis M, Alexopoulou L, Episkopou V, Kollias G. Immune and inflammatory responses in TNF alpha-deficient mice: a critical requirement for TNF alpha in the formation of primary B cell follicles, follicular dendritic cell networks and germinal centers, and in the maturation of the humoral immune response. J Exp Med 1996; 184: 1397-1411.

24. Beraza N, Malato Y, Sander L, Al-Masaoudi M, Freimuth J, Riethmacher D et al. Hepatocyte-specific NEMO deletion promotes NK/NKT cell- and TRAIL-dependent liver damage. J Exp Med 2009; 206: 1727-1737.

25. Wang K. Molecular mechanisms of hepatic apoptosis. Cell Death Dis 2014; 5: e996.

26. Schattenberg JM, Schuchmann M, Galle PR. Cell death and hepatocarcinogenesis: Dysregulation of apoptosis signaling pathways. J Gastroenterol Hepatol 2011; 26(Suppl 1): 213-219.

27. Pasparakis M. Regulation of tissue homeostasis by NF-kappaB signalling: implications for inflammatory diseases. Nat Rev Immunol 2009; 9: 778-788.

28. Liedtke C, Bangen J-M, Freimuth J, Beraza N, Lambertz D, Cubero F et al. Loss of caspase-8 protects mice against inflammation-related hepatocarcinogenesis but induces non-apoptotic liver injury. Gastroenterology 2011; 141: 2176-2187.

29. Cubero F, Singh A, Borkham-Kamphorst E, Nevzorova Y, Al Masaoudi M, Haas U et al. TNFR1 determines progression of chronic liver injury in the IKK $\gamma / \mathrm{Nemo}$ genetic model. Cell Death Differ 2013; 20: 1580-1592.
30. Meylan F, Richard AC, RM. Siegel. TL1A and DR3, a TNF family ligand-receptor pair that promotes lymphocyte costimulation, mucosal hyperplasia, and autoimmune inflammation. Immunol Rev 2011; 244: 188-196.

31. Kellendonk C, Opherk C, Anlag K, Schütz G, Tronche F. Hepatocyte-specific expression of Cre recombinase. Genesis 2000; 26: 151-153.

32. Mc Guire C, Volckaert T, Wolke U, Sze M, de Rycke $R$, Waisman A et al. Oligodendrocyte-specific FADD deletion protects mice from autoimmune-mediated demyelination. J Immunol 2010; 185: 7646-7653.

33. Van Hauwermeiren F, Armaka M, Karagianni N, Kranidioti K, Vandenbroucke R, Loges S et al. Safe TNF-based antitumor therapy following p55TNFR reduction in intestinal epithelium. J Clin Invest 2013; 123: 2590-2603.

34. Grosse-Wilde A, Voloshanenko O, Bailey SL, Longton GM, Schaefer U, Csernok Al et al. TRAIL-R deficiency in mice enhances lymph node metastasis without affecting primary tumor development. J Clin Invest 2008; 118: 100-110.

35. Hao Z, Hampel B, Yagita H, Rajewsky K. T cell-specific ablation of Fas leads to Fas ligandmediated lymphocyte depletion and inflammatory pulmonary fibrosis. J Exp Med 2004; 199: 1355-1365.

36. Mombaerts P, lacomini J, Johnson RS, Herrup K, Tonegawa S, Papaioannou VE. RAG-1-deficient mice have no mature $B$ and $T$ lymphocytes. Cell 1992; 68: 869-877.

Supplementary Information accompanies this paper on Cell Death and Differentiation website (http://www.nature.com/cdd) 